\title{
Inhibition of tamoxifen's therapeutic effects by emodin in estrogen receptor-positive breast cancer cell lines
}

\author{
Yun Gyoung Kim ${ }^{1,2, *}$, Yoon Hwa Park, ${ }^{3, *}$ Eun Yoel Yang ${ }^{4}$, Won Seo Park ${ }^{5}$, Kyoung Sik Park ${ }^{6,7}$ \\ ${ }^{1}$ Department of Surgery, Bundang Jesang General Hospital, Seongnam, Korea \\ ${ }^{2}$ Clinical Science, Department of Medicine, The Graduate School of Konkuk University, Seoul, Korea \\ ${ }^{3}$ Division of Radiation Cancer Research, Korea Institute of Radiological and Medical Sciences, Seoul, Korea \\ ${ }^{4}$ Ewha Womans University Mokdong Hospital/Cancer Center for Women, Breast and Thyroid Cancer Center, Seoul, Korea \\ ${ }^{5}$ Department of Surgery, Kyung Hee University School of Medicine, Seoul, Korea \\ ${ }^{6}$ Department of Surgery, Konkuk University School of Medicine, Seoul, Korea \\ ${ }^{7}$ Research Institute of Medical Science, Konkuk University School of Medicine, Seoul, Korea
}

\begin{abstract}
Purpose: This study was aimed to investigate the combination effect of endoxifen and emodin on estrogen receptor (ER) positive breast cancer cell lines and to explain the mechanism of the combination effect.

Methods: We conducted this study on MCF-7 (ER+/human epidermal growth factor receptor-2 [HER2]-), T47D (ER+/ HER2-), ZR-75-1 (ER+/HER2+), and BT474 (ER+/HER2+) cell lines, which confirmed combination effect of endoxifen and emodin. Optimal concentrations for combination were determined to study the effects on proliferation of MCF-7 and ZR75-1 cells. Analysis of the combination effect was carried out in the CompuSyn software. The combination of downstream mechanisms, and combined effects of other similar compounds were tested on the MCF-7 and ZR 75-1 cell lines. Protein expression was confirmed by western blot.

Results: The combination of endoxifen and emodin had antagonistic effects on MCF-7 and ZR-75-1cell lines (combination index $>1$ 1). We validated the antagonistic effect in T47D and BT474 cell lines. During the combined treatment, the results showed elevated amounts of cyclin D1 and phosphorylated extracellular signal-regulated kinase (pERK). Analysis of drug interactions showed antagonistic effect between endoxifen and chemical compounds similar to emodin, such as chrysophanol or rhein, in MCF-7 and ZR-75-1 cells.

Conclusion: Addition of emodin attenuated tamoxifen's treatment effect via cyclin D1 and pERK up-regulation in ERpositive breast cancer cell lines.
\end{abstract}

[Ann Surg Treat Res 2019;97(5):230-238]

Key Words: Breast neoplasm, Cyclin D1, Emodin, Phytoestrogens, Tamoxifen

\section{INTRODUCTION}

The proportion of patients with estrogen receptor (ER)-positive breast cancer increased from $49.6 \%$ in 1996 to $70.0 \%$ in 2010 [1]. In patients with hormone receptor-positive (ER-positive and/or progesterone receptor; [PR] positive) breast cancer, antiestrogen therapy is the main treatment. The mechanism of action of tamoxifen is mediated by competitive binding to ER. Tamoxifen inhibits estrogen-related gene expression and blocks G1 phase of the cell cycle [2]. There was a randomized trial of tamoxifen for the treatment of early breast cancer. The proportion of recurrence for women with ER-positive breast
Received September 9, 2019, Revised October 8, 2019,

Accepted October 13, 2019

\section{Corresponding Author: Kyoung Sik Park}

Department of Surgery and Research Institute, Konkuk University

School of Medicine, 120 Neungdong-ro, Gwangjin-gu, Seoul 05030, Korea

Tel: +82-2-2030-7697, Fax: +82-2-2030-7346

E-mail: ks2002p@hanmail.net

ORCID: https://orcid.org/0000-0001-9806-9839
*Yun Gyoung Kim and Yoon Hwa Park contributed equally to this study as co-first authors.

Copyright (c) 2019, the Korean Surgical Society

(c) Annals of Surgical Treatment and Research is an Open Access Journal. All articles are distributed under the terms of the Creative Commons Attribution NonCommercial License (http://creativecommons.org/licenses/by-nc/4.0/) which permits unrestricted non-commercial use, distribution, and reproduction in any medium, provided the original work is properly cited. 
cancer who used tamoxifen for 5 years was reduced by $50 \%$ $(\mathrm{P}<0.01)$, and the mortality rate was reduced by $28 \%$. On the other hand, in women with ER-negative breast cancer, the benefits of tamoxifen are unclear [3]. The antiestrogen therapy such as tamoxifen or an aromatase inhibitor lasting for 5 years reduces breast cancer recurrence and increases overall survival. Thus, tamoxifen has become the global standard of care for premenopausal patients with breast cancer. The recommendation of treatment takes into consideration that after 5 years, patients should receive additional antiestrogen therapy for 10 years [4]. However, adjuvant hormone therapy was discontinued for various reasons. Aiello Bowles et al. [5] reported discontinuation of hormone therapy and related adverse effects among patients with early breast cancer. The researchers reported that $18.2 \%$ of the patients had discontinued hormone therapy. Patients who discontinued treatment experienced adverse effects in many cases, with $41.8 \%$ reporting hormone/menopause-related symptoms.

Emodin (1,3,8-trihydroxy-6-methylanthraquinone) is a natural anthraquinone and phytoestrogen isolated from herbs [6,7]. Emodin has been reported to have antibacterial [8], anti-inflammatory [9], and anticancer effects [7,10]. Emodin can downregulate certain inflammatory markers, such as interleukin (IL)-1 $\beta$, IL-6, IL-8, nuclear factor-kappa B, and tumor necrosis factor-alpha, and so on [11]. In addition, emodin has anti-inflammatory effects in several disorders, such as pancreatitis, arthritis, asthma, atherosclerosis, and glomerulonephritis [9]. The anticancer effect of emodin was reported for hepatocellular carcinoma cells [10], tongue squamous cancer cells [7], and pancreatic cancers [12] via apoptosis.

The aims of the present study were to investigate the combination effect of tamoxifen and emodin on ER-positive breast cancer cell lines and to explain the mechanism of the combination effect. In this study, we looked at patients with tamoxifen for passible material use to improve their hormone/ menopause-related symptoms.

\section{METHODS}

\section{Cell culture}

MCF-7, T47D, and BT-474 breast cancer cell lines were purchased from the American Type Culture Collection (Manassas, VA, USA). The ZR-75-1 cell line was purchased from KOREAN CELL LINE BANK (KCLB; Seoul, Republic of Korea). Molecular classification of MCF-7 and T47D cell lines are "ER-positive and HER2 negative". ZR-75-1 and BT-474 cell lines are "ER-positive and HER2 positive" [13]. The MCF-7 cell line was grown in Dulbecco's Modified Eagle's Medium (Welgene, Daegu, Republic of Korea), whereas ZR-75-1, T-47D, and BT-474 cell lines were grown in the Roswell Park Memorial Institute 1640 culture medium (Welgene, Daegu, Republic of Korea) with 10\% of fetal bovine serum (Corning life sciences, USA).

\section{Reagents}

Antibodies against $E R \alpha$ and $\beta$-actin were purchased from Santa Cruz Biotechnology (Santa Cruz, CA, USA) and those recognizing epidermal growth factor receptor (EGFR), cyclin D1, and phosphorylated extracellular signal-regulated kinase (p-ERK) were purchased from Cell Signaling Technology (Cell Signaling, Beverly, MA, USA). We used endoxifen instead of tamoxifen for our study to mimic the in vivo environment. Endoxifen is a therapeutically active metabolite of tamoxifen [14]. Endoxifen was purchased from Sigma Chemical Co. (St. Louis, MO, USA). Emodin, rhein (1,8-dihydroxy-3-carboxyl9,10-anthraquinone) and chrysophanol (1,8-dihydroxy-3methylanthraquinone) were purchased from Sigma-Aldrich.

\section{Measurement of cell viability}

Cell viability was measured using the EZ-Cytox cell viability assay kit (Itsbio, Seoul, Korea). The cells were incubated for 1 hour at $37^{\circ} \mathrm{C}$ in a serum-free medium diluted with 1 kit reagent. Next, harvested cells resuspended in the media were carefully moved to empty 96- well plate and absorbance was measured using a microplate reader at $450 \mathrm{~nm}$.

\section{Isobologram analysis}

Cell viability data were analyzed using in the CompuSyn software (ComboSyn, Inc., Paramus, NJ, USA). This software determines the combined effects of drugs: whether they are synergistic, antagonistic, or additive. The software was developed by Dr. Dorothy Chou in 2005. This software is based on the median-effect principle of the mass-action law [15]. In the isobologram graph, an antagonistic effect is above the oblique line (combination index [CI] $>1$ ), a synergistic effect is below the oblique line $(\mathrm{CI}<1)$, and an additive effect is on the line $(C I=1)[15,16]$.

\section{Western blot analysis}

Cell lines were harvested and dissolved in radioimmunoprecipitation assay buffer $(50 \mathrm{mM}$ Tris- $\mathrm{HCl} \mathrm{pH} 7.5,150 \mathrm{mM}$ $\mathrm{NaCl}, 1 \%$ Nonidet P40, $0.5 \%$ sodium deoxycholate, and $0.1 \%$ sodium dodecyl sulfate [SDS], supplemented with a protease inhibitor cocktail) (Gendepot, Katy, TX, USA). Equal amounts of protein $(20-50 \mu \mathrm{g})$ were separated by SDS-polyacrylamide gel electrophoresis and transferred on to a nitrocellulose membrane. Membranes were blocked by incubating them with 2.5\% skim milk for 1 hour and then incubated overnight with the appropriate primary antibodies (diluted 1:1,000), followed by a 1.5 -hour reaction with the secondary antibody (diluted 1:10,000). Immunoreactive proteins were visualized by means of the enhanced-chemiluminescence reagent (Amersham Bio- 

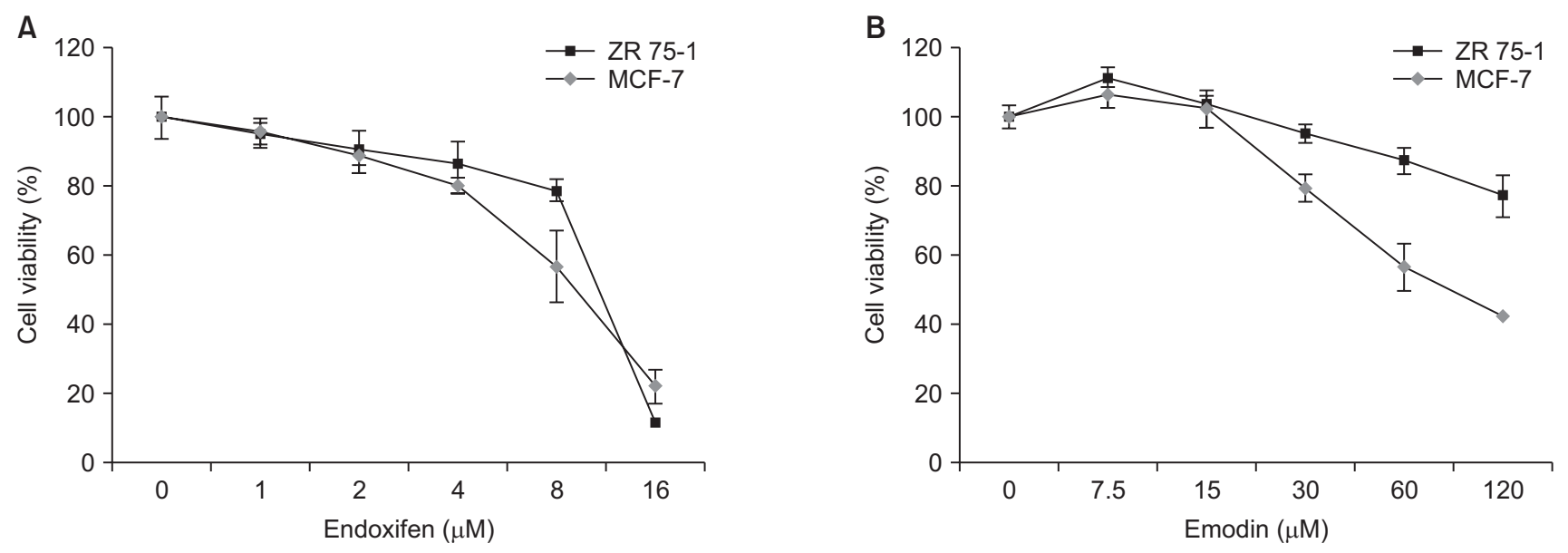

Fig. 1. Analysis of cell viability in MCF-7 and ZR75-1 breast cancer cell lines. Cell viability was analyzed using the EZ-Cytox cell viability assay kit. The cell lines were treated with 0-16 $\mu \mathrm{M}$ endoxifen for 48 hours (A) and 0-120 $\mu \mathrm{M}$ emodin for 48 hours (B). After analysis using EZ-Cytox, the cytotoxic concentrations of endoxifen $(4 \mu \mathrm{M})$ and emodin (60 $\mu \mathrm{M})$ were obtained.

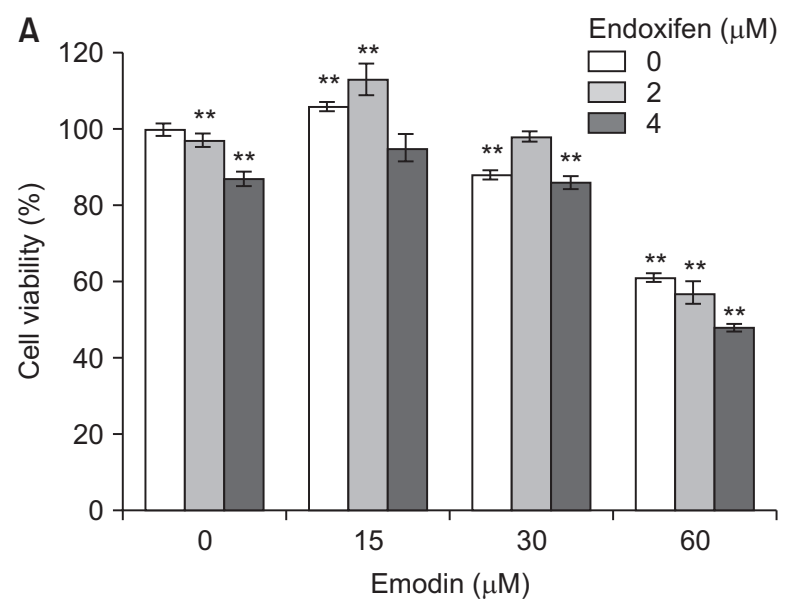

Emodin $(\mu \mathrm{M})$

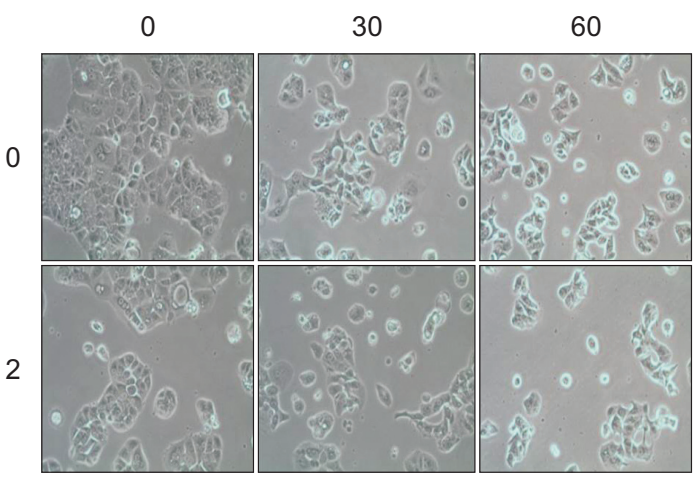

Endoxifen $(\mu \mathrm{M})$

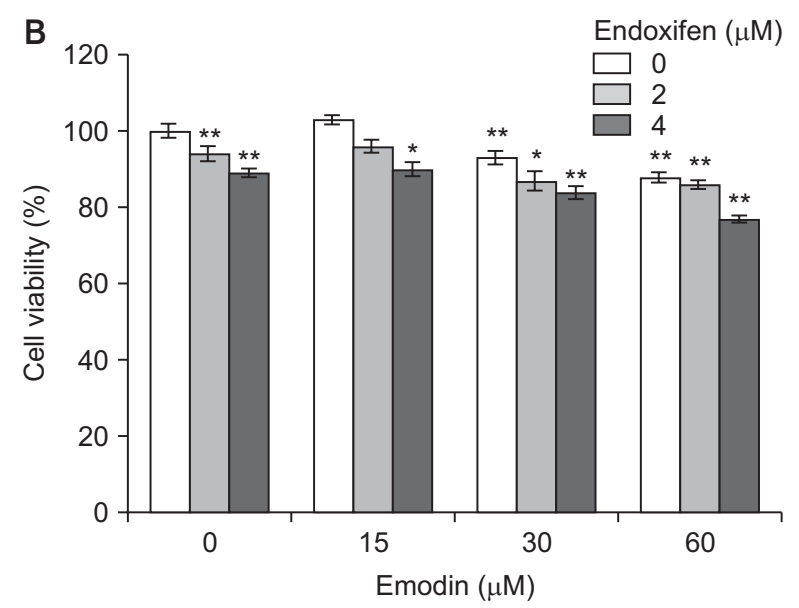

Emodin $(\mu \mathrm{M})$

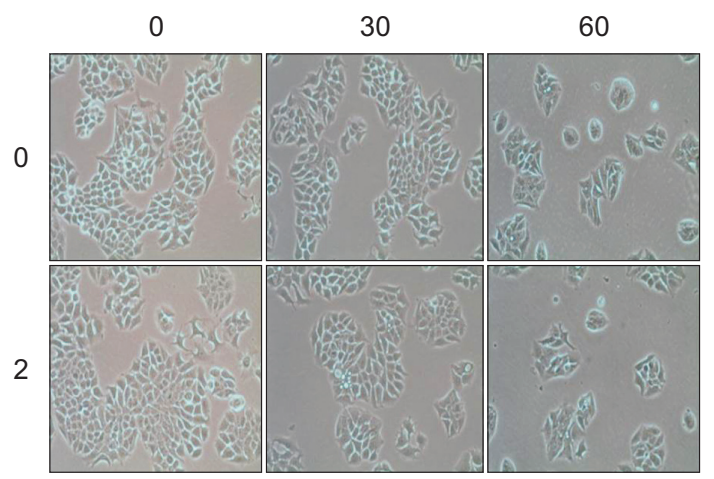

Endoxifen $(\mu \mathrm{M})$

Fig. 2. Cell viability and microscopic feature after combined drug combination. After treatment with the drug combination, cell viability was analyzed using the EZ-Cytox assay. Combinations emodin $(0,15,30,60 \mu M)$ and endoxifen $(0,2,4 \mu M)$ were applied for 48 hours. Cell viability decreased gradually with increasing drug dose in the MCF-7 breast cancer cell line (A) and the ZR 75-1 breast cancer cell line (B). Cell morphology was observed after 48 hours of incubation with the drug combinations ( $\times 250 ; \mathrm{A}, \mathrm{MCF}-7 ; \mathrm{B}, \mathrm{ZR}-75-1) . * \mathrm{P}<0.05, * * \mathrm{P}<0.01$. 
sciences, Little Chalfont, UK).

\section{Statistical analysis}

All the results were compiled from a minimum of 3 independent experiments. Student t-test was performed to compare results of untreated (control) and treated group. Data were analyzed in the IBM SPSS ver. 18.0 (IBM Co., Armonk, NY, USA). Statistical significance was set to $P<0.05$.

This study was exempted from review by the Institutional Review Board of the Konkuk University (study number: 7001355-201507-E-036).

\section{RESULTS}

\section{Combined effects of endoxifen and emodin on human breast cancer cell lines}

The ER-positive/HER2 negative; MCF-7, and ER-positive/HER2 positive; ZR 75-1, breast cancer cell lines were treated with a variety of concentrations of emodin or endoxifen for 48 hours. Cell viability findings are shown in Fig. 1A and B. The EZ-Cytox assay determined the cytotoxic concentrations of emodin and endoxifen (causing an approximately $20 \%$ reduction in cell viability) they were 60 and $4 \mu \mathrm{M}$, respectively. We decided to test combinations of concentrations of emodin $(15,30,60$ $\mu \mathrm{M})$ and of endoxifen $(2,4 \mu \mathrm{M})$. Cell viability and microscopic findings for cells treated with the various combinations are shown in Fig. $2 A$ and B. Emodin $(60 \mu \mathrm{M})$ and endoxifen $(4 \mu \mathrm{M})$ resulted in cell viability of $47.8 \%$ of MCF-7 cells after 48 hours (as compared to $60 \mu \mathrm{M}$ Emodin alone: $56.5 \%$, or $4 \mu \mathrm{M}$ Endoxifen alone: $80.6 \%$ ). In ZR-75-1 breast cancer cell lines, emodin (60 $\mu \mathrm{M})$ and endoxifen $(4 \mu \mathrm{M})$ yielded cell viability of $77.2 \%$ after 48 hours (as compared to $60 \mu \mathrm{M}$ Emodin alone: $87.4 \%, 4 \mu \mathrm{M}$ endoxifen alone: $86.6 \%$ ).

The effects of the drug combinations were calculated in the CompuSyn software (Fig. 3A, B). In the MCF-7 breast cancer cell line, the $\mathrm{CI}$ value was 1.06586 between endoxifen $(4 \mu \mathrm{M})$ and emodin $(60 \mu \mathrm{M})$. In ZR-75-1 cells, the CI value was 1.20447 under the same conditions. Both $\mathrm{CI}$ values were $>1$, indicating an antagonistic effect between emodin and endoxifen in MCF-7 and ZR-75-1 breast cancer cells.

Subsequently, we validated the antagonistic effect in other breast cancer cell lines. The ER-positive/HER2 negative breast cancer cell line, T47D, showed similar antagonistic effects (Fig. $4 \mathrm{~A})$. Emodin $(60 \mu \mathrm{M})$ and endoxifen $(4 \mu \mathrm{M})$ yielded cell viability of $70.5 \%$ of T47D cells after 48 hours (as compared with $60 \mu \mathrm{M}$ Emodin alone: $99.2 \%$, or $4 \mu \mathrm{M}$ endoxifen alone: $71.8 \%$ ). The $\mathrm{CI}$ value was calculated and found to be 1.05637 . The ER-positive/ HER2 positive breast cancer cell line, BT-474, also manifested an antagonistic effect (Fig. 4B). Emodin $(60 \mu \mathrm{M})$ and endoxifen (4 $\mu \mathrm{M}$ ) yielded cell viability of $41 \%$ of BT474 cells after 48 hours (as compared with $60 \mu \mathrm{M}$ emodin alone: $73.6 \%$, or $4 \mu \mathrm{M}$ endoxifen alone: 97.0\%). The CI value was found to be 1.50427 .

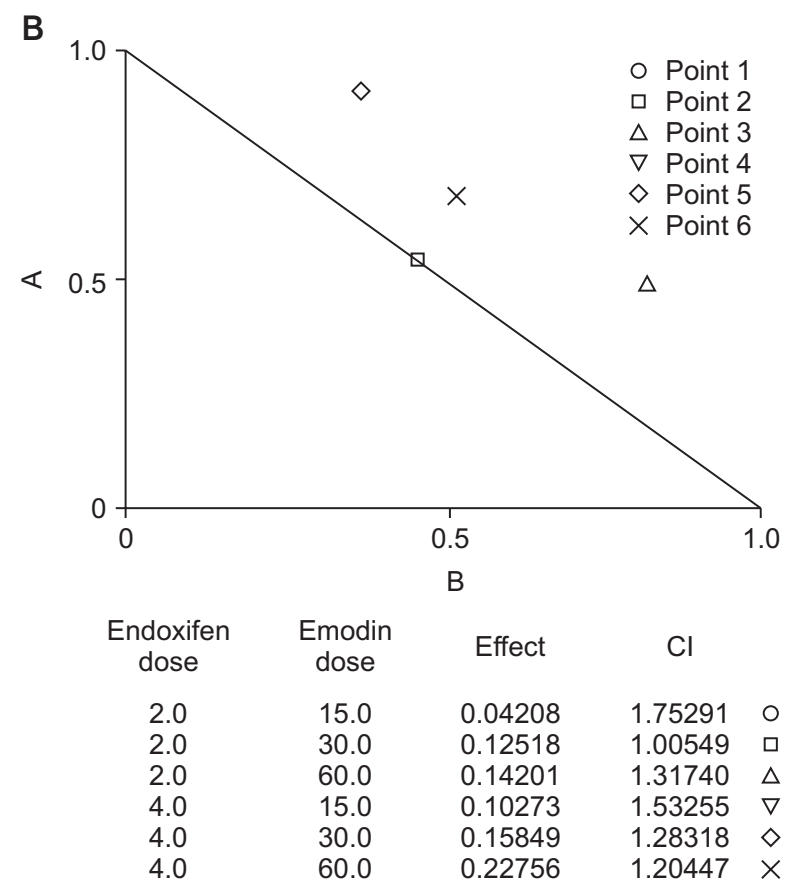

Fig. 3. Isobologram analysis using CompuSyn software. Isobologram analysis was based on the results of cell viability after treatment using the drug combination. The MCF-7 breast cancer cell line (A) and the ZR 75-1 breast cancer cell line (B) had combination index $(\mathrm{Cl})$ values $>1$. These results indicated an antagonistic effect in the 2 cell lines. 

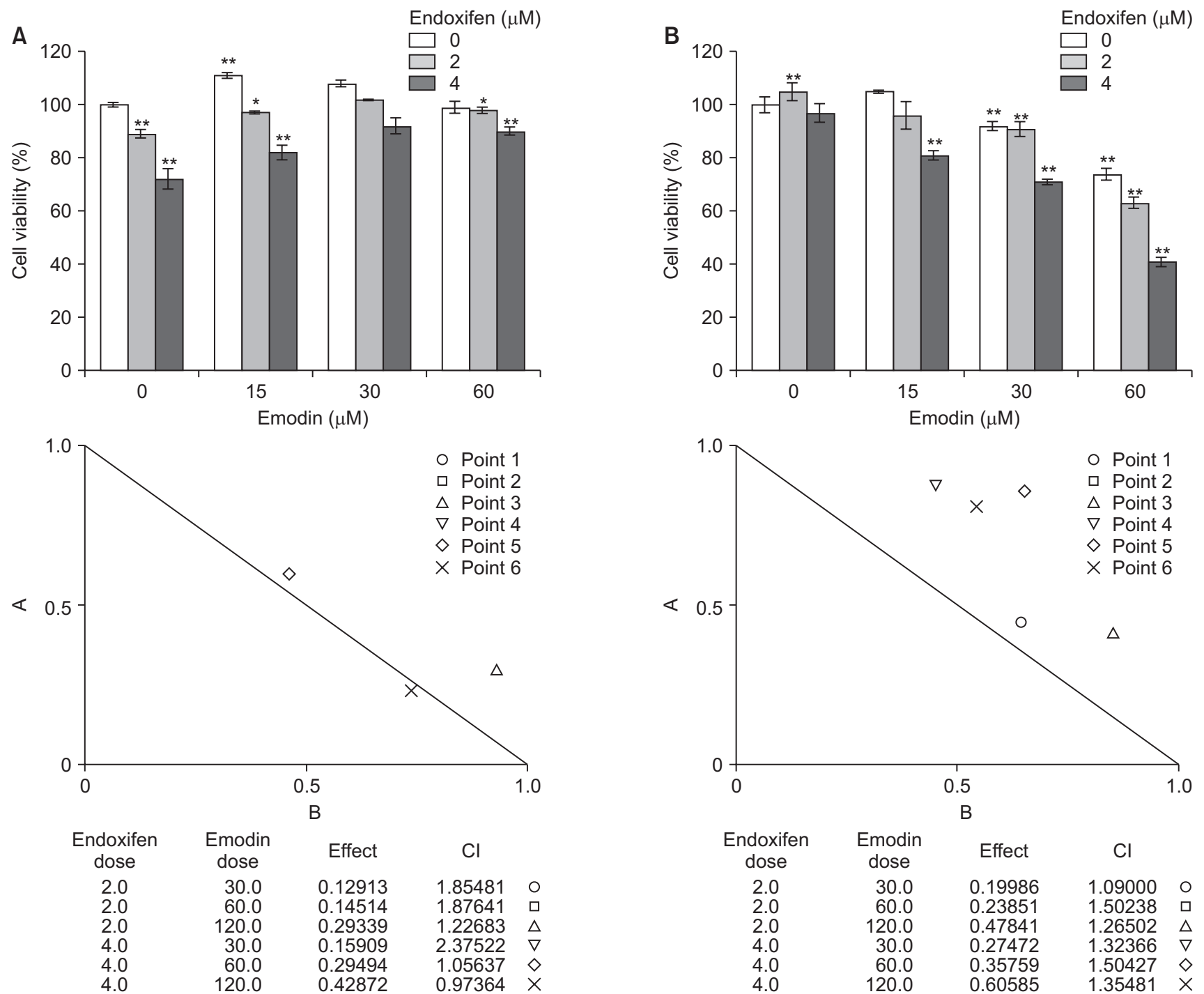

Fig. 4. Validation of the antagonistic effects on other breast cancer cell lines. Cell viability was analyzed using the EZ-Cytox assay. Isobologram analysis was performed using the CompuSyn program. The T47D breast cancer cell line (A) and the BT-474 breast cancer cell line (B) also showed the antagonistic effect between endoxifen and emodin. $\mathrm{Cl}$, combination index. $* \mathrm{P}<0.05$, $* * \mathrm{P}<0.01$.

\section{Analysis of the downstream mechanism of the antagonistic effect}

To confirm the mechanism of the antagonistic effect, we performed western blotting assays. The MCF-7 and ZR-75-1 breast cancer cell lines were treated with emodin and endoxifen for 48 hours, and the harvested proteins were analyzed by western blotting. Treatment with the endoxifen and emodin combination; increased cyclin D1 and p-ERK amounts (Fig. 5).

\section{Combination effects for similar chemical compounds on breast cancer cell lines}

Subsequently, we studied the drug interactions between chemical compounds that are similar to emodin and endoxifen. Emodin, chrysophanol, and rhein are categorized as

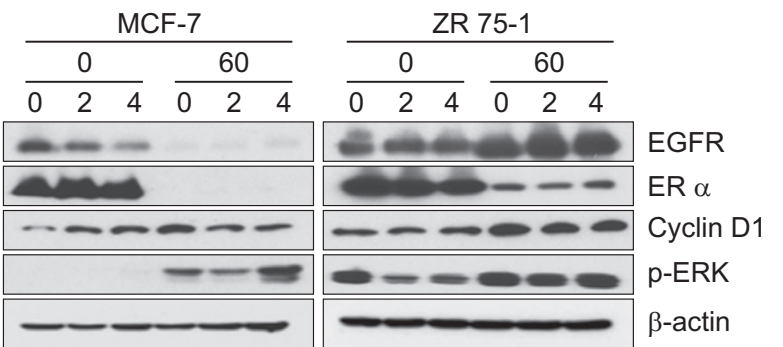

Fig. 5. Western blotting analysis of cells in response to the combination of endoxifen and emodin. The breast cancer cell lines were treated endoxifen $(0,2,4 \mu \mathrm{M})$ and emodin $(0,60 \mu \mathrm{M})$. After 48 hours, protein levels in harvested cells were analyzed using western blotting analysis. $\beta$-actin was used as a loading control - EGFR; EGFR, epidermal growth factor receptor; ER $\alpha$, estrogen receptor alpha; $p$-ERK, phosphorylated extracellular signal-regulated kinase. 
anthraquinones. The MCF-7 and ZR-75-1 breast cancer cell lines were treated with several concentrations of these compounds combined with endoxifen. Figs. 6 and 7 show cell viability and isobolograms for the drug interactions. The MCF-7 breast cancer cell line demonstrated antagonistic effects of the combinations of chrysophanol or rhein with endoxifen. The cell viability of MCF-7 cells was $86.2 \%$ when they were treated with endoxifen $(4 \mu \mathrm{M})$ and chrysophanol $(60 \mu \mathrm{M})$ for 48 hours (as compared with $60 \mu \mathrm{M}$ chrysophanol alone: $88.0 \%, 4 \mu \mathrm{M}$ endoxifen alone: $88.0 \%$ ). The $\mathrm{CI}$ value was found to be 2.78039 . The cell viability of MCF-7 cells was $95.4 \%$ when they were treated with endoxifen $(4 \mu \mathrm{M})$ and rhein $(60 \mu \mathrm{M})$ for 48 hours (as compared with $60 \mu \mathrm{M}$ rhein alone: $87.8 \%$, or $4 \mu \mathrm{M}$ endoxifen alone: $89.9 \%$ ). The CI value was calculated and found to be 3.09017 .

Chrysophanol and rhein had antagonistic effects on ZR-751 breast cancer cell line. The cell viability of ZR75-1 cells was $86.7 \%$ when treated with endoxifen $(4 \mu \mathrm{M})$ and chrysophanol $(60$ $\mu \mathrm{M}$ ) for 48 hours (as compared with $60 \mu \mathrm{M}$ chrysophanol alone: $97.7 \%$, or $4 \mu \mathrm{M}$ endoxifen alone: $87.5 \%)$. The $\mathrm{CI}$ value was found to be 1.63508 . The combination of endoxifen $(4 \mu \mathrm{M})$ and rhein $(60 \mu \mathrm{M})$ yielded a cell viability of $97.2 \%$ of MCF-7 cells after 48 hours (as compared with $60 \mu \mathrm{M}$ rhein alone: $96.5 \%$, or $4 \mu \mathrm{M}$ endoxifen alone: $88.6 \%$ ). The $\mathrm{CI}$ value was calculated and found to be 3.72066 .
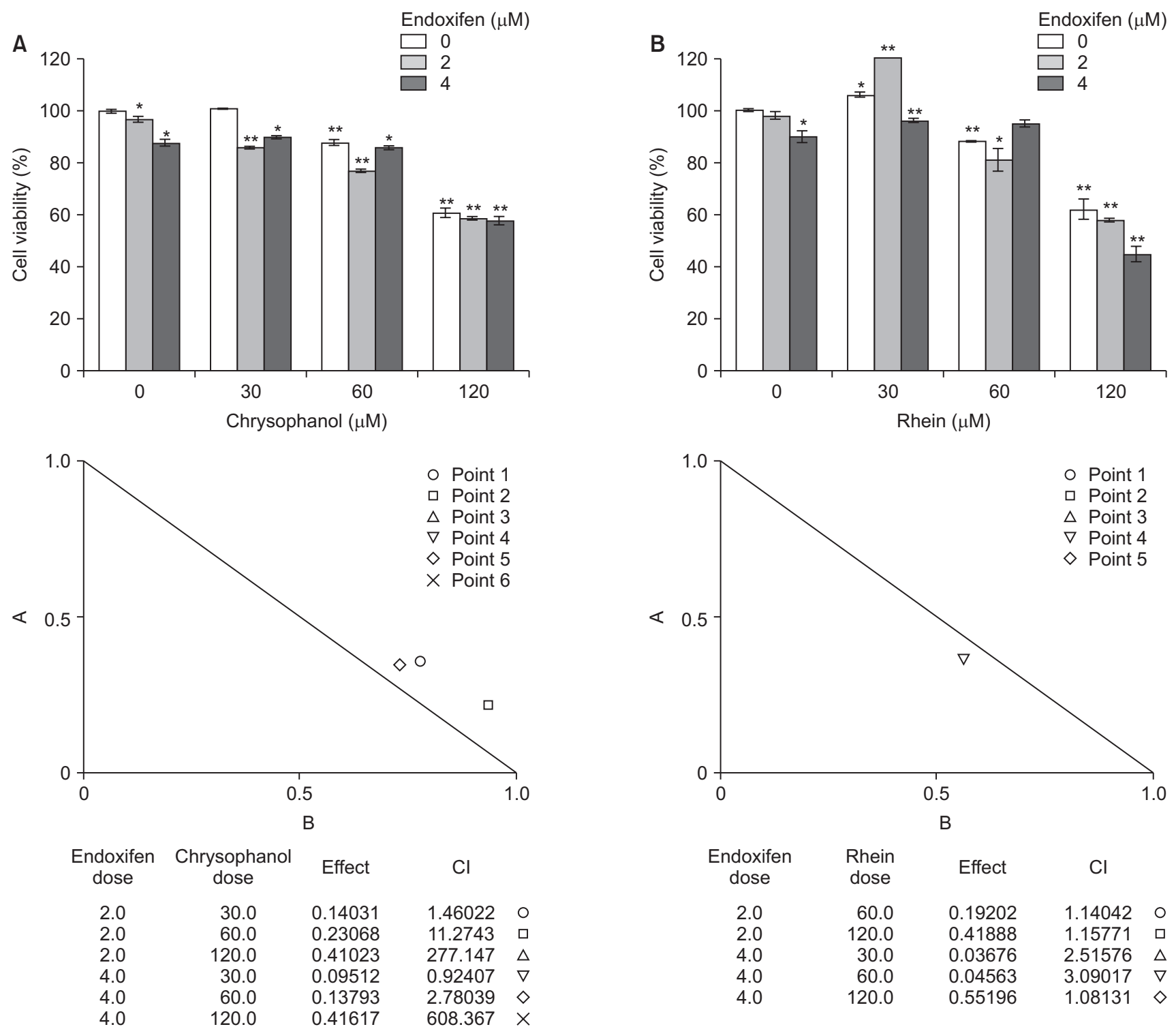

Fig. 6. Cell viability and isobologram analysis of MCF-7 breast cancer cells treated with combinations of endoxifen and other compounds. Cell viability was analyzed using the EZ-Cytox assay. Isobologram analysis was performed using the CompuSyn program. The MCF-7 breast cancer cell line showed an antagonistic effect toward endoxifen with chrysophanol or rhein. Cl, combination index. ${ }^{*} \mathrm{P}<0.05,{ }^{*} \mathrm{P}<0.01$. 

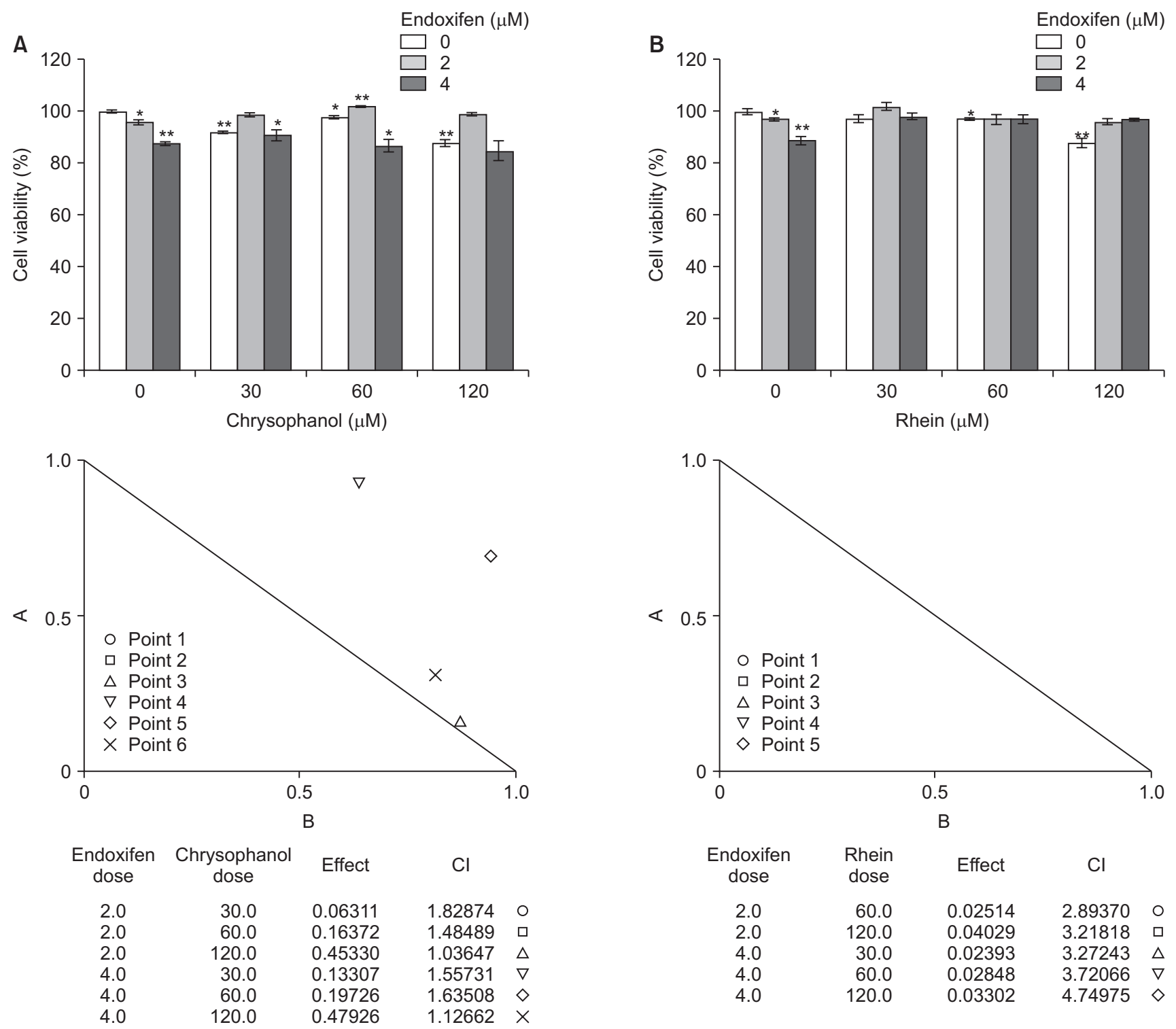

Fig. 7. Cell viability and isobologram analysis with drug combination between endoxifen and other compounds in ZR75-1 breast cancer cell line Cell viability analyzed by EZ-Cytox assay. Isobologram analysis was used to Compusyn program. ZR 75-1 breast cancer cell line showed antagonistic effect between endoxifen and chysophanol or rhein. Cl, combination index. $* \mathrm{P}<0.05, * * \mathrm{P}<0.01$.

\section{DISCUSSION}

The results of this study reveal antagonistic effects of emodin and endoxifen when used in combination against breast cancer cell lines. These antagonistic effects are associated with up-regulation of cyclin D1 and p-ERK. These results suggest that emodin, one of phytoestrogens, may interfere with the therapeutic effect of tamoxifen against ER-positive breast cancer cell lines.

In this study, we tested the drug combination on MCF-7 and ZR-75-1 breast cancer cell lines and validated the results in T47D and BT-474 breast cancer cell lines. The MCF-7 breast cancer cell line originated from the pleural effusion of a 69 -year-old patient with metastatic breast cancer [17]. MCF-7 cells are widely used as an ER-positive cell line [13]. The T47D breast cancer cell line originated from the pleural effusion of a 54-year-old patient with metastatic breast cancer [18]. The T47D breast cancer cell line expresses high levels of PR. Thus, T47D cells are considered a major model for the research one progesterone in human cells [19]. The MCF-7 and T47D breast cancer cell lines are classified as luminal A (ER+, PR+/-, HER2-) [13]. The ZR-75-1 breast cancer cell line originated in the ascites of a 47-year-old patient with metastatic breast cancer [18] and is regarded as a luminal B (ER+/HER2+) subtype [13]. The BT-474 breast cancer cell line 
originated from a primary invasive ductal carcinoma of a 60-year-old patient with breast cancer [20] and is also a luminal B subtype (ER+/HER2+) [13]. In our study, MCF-7, T47D, ZR-751 , and BT474 breast cancer cell lines all showed the antagonistic effects of our drug combination. According to these results, the combination of endoxifen and emodin has an antagonistic effect regardless of HER2 status.

Cyclin D1 forms a complex with cyclin-dependent kinase 4 (CDK4). The cyclin D1-CDK4 complex promotes S-phase entry by triggering E2F-dependent gene transcription [21]. In the western blotting analysis an increased cyclin D1 amount was observed in the cells treated with the drug combination. This result suggests that the drug combination promotes entry into the S-phase of the cell cycle. Cyclin D1 overexpression has been noted in breast carcinoma [21]. In the ZR-75-1 breast cancer cell line, EGFR expression increased in response to the drug combination. EGFR is composed of an extracellular region, a transmembrane segment, a juxtamembrane segment, a kinase domain, and sites of tyrosine phosphorylation. The extracellular region of EGFR undergoes dimerization, resulting in transmission of downstream signals [22]. The RasRaf-mitogen-activated protein kinase (MAPK) pathway, the phosphatidylinositol 3-kinase (PI3K)-Akt-mammalian target of rapamycin (mTOR) pathway, phospholipase $\mathrm{C}_{\gamma}$ pathway, the signal transducer and activator of transcription pathway, and the Src kinase pathway are all downstream effectors of EGFR [12]. EGFR plays an important role in many cancers, where it stimulates tumor growth, metastasis, and angiogenesis via these signaling cascades [23]. The Ras-Raf-MAPK pathway controls cell proliferation and survival. After phosphorylation of EGFR, EGFR forms a complex with proteins Grb2 and Sos, or interacts with them through the adaptor molecule Shc. This interaction recruits Ras-GDP and activates Ras-GTP. RasGTP activates Raf-1, and then stimulates Erk-1 and Erk-2. These 2 acts as transcription factors in the nucleus and ultimately promote cell proliferation and survival. The PI3K-Akt-mTOR pathway is associated with cell growth, apoptosis resistance, cell invasion, and cell migration [12]. PI3K phosphorylates phosphatidylinositol diphosphate to phosphatidylinositol triphosphate (PIP3). PIP3 activates the oncogene Akt. Akt inhibits tuberous sclerosis complex-2. As a result, Akt activates mTOR, which has effects on cell survival, cell proliferation, and metabolism [24]. In our study, increased p-ERK levels could explain the antagonistic effects of endoxifen and emodin on cell proliferation.

We performed drug interaction analyses between endoxifen and anthraquinone compounds similar to emodin (chrysophanol and rhein). Anthraquinones are benzoquinone derivatives that are synthesized by diverse pathways in plants and fungi. Anthraquinones have antimutagenic and anticarcinogenic activities. In addition, emodin, chrysophanol, and rhein have inhibitory effects on benzo[ $\alpha]$ pyrenemediated DNA damage in the HepG2 hepatoma cell line [25]. Nevertheless, in this study, emodin, chrysophanol, and rhein showed effects that are antagonistic to endoxifen's action on MCF-7 and ZR-75-1 breast cancer cell lines. Although we did not perform a mechanistic analysis of this finding, we hypothesized that the mechanism is similar to that of emodin.

Some investigators reported inhibitory effects of a combination of tamoxifen and genistein [26,27]. Genistein is a phytoestrogen from soy that has been demonstrated to potentially inhibit the growth of breast cancer cell lines in vitro and to provide a relief of postmenopausal symptoms. Jones et al. showed that genistein inhibits tamoxifen's effects on the T47D breast cancer cell line. Tamoxifen $(1.0 \mu \mathrm{M})$ decreased cell proliferation (92.8\%) compared with the control (100\%). By contrast, the combined treatment with genistein and tamoxifen improved proliferation (96.7\%) of the T47D breast cancer cell line. This result was interpreted as a reversal of cell cycle arrest: Tamoxifen induces G1 arrest; however, the combined treatment with genistein and tamoxifen reverses the G1 arrest, thereby normalizing the cell cycle [26]. Ju et al. [27] determined whether genistein negates the inhibitory effect of tamoxifen on the growth of MCF-7 breast cancer cells in nude mice. They studied the effect of the drug under several conditions and showed antagonistic effects. The combination treatment with genistein and tamoxifen resulted in a significantly larger tumor surface area compared with tamoxifen alone $\left(2.5 \mathrm{TEG}, 75.1 \mathrm{~mm}^{2}\right.$; 5 TEG, $50.9 \mathrm{~mm}^{2} ; 2.5 \mathrm{TE}, 14.4 \mathrm{~mm}^{2} ; 5 \mathrm{TE}, 13.7 \mathrm{~mm}^{2}$ ). This study revealed that the combination treatment recovered pS2 expression via cyclin D1 overexpression as compared to the treatment with tamoxifen alone. Thus, these 2 studies verified the antagonistic effect between tamoxifen and other phytoestrogens, in agreement with our results.

In conclusion, our data indicate that the combination treatment with endoxifen and emodin has an antagonistic effect via cyclin D1 and pERK overexpression in ER-positive breast cancer cell lines. These results suggest that emodin may attenuate tamoxifen's therapeutic effects. Therefore, patients with ERpositive breast cancer should be careful when consuming phytoestrogens.

\section{CONFLICTS OF INTEREST}

No potential conflict of interest relevant to this article was reported.

\section{ACKNOWLEDGEMENTS}

This paper was supported by Konkuk University in 2018. 
1. Ko BS, Noh WC, Kang SS, Park BW, Kang EY, Paik NS, et al. Changing patterns in the clinical characteristics of Korean breast cancer from 1996-2010 using an online nationwide breast cancer database. J Breast Cancer 2012;15:393-400.

2. Osborne CK. Tamoxifen in the treatment of breast cancer. N Engl J Med 1998;339: 1609-18.

3. Tamoxifen for early breast cancer: an overview of the randomised trials. Early Breast Cancer Trialists' Collaborative Group. Lancet 1998:351:1451-67.

4. Burstein HJ, Temin S, Anderson H, Buchholz TA, Davidson NE, Gelmon KE, et al. Adjuvant endocrine therapy for women with hormone receptor-positive breast cancer: american society of clinical oncology clinical practice guideline focused update. J Clin Oncol 2014:32:225569.

5. Aiello Bowles EJ, Boudreau DM, Chubak J, Yu O, Fujii M, Chestnut J, et al. Patientreported discontinuation of endocrine therapy and related adverse effects among women with early-stage breast cancer. J Oncol Pract 2012;8:e149-57.

6. Jiao Y, Zuo Y. Ultrasonic extraction and HPLC determination of anthraquinones, aloe-emodine, emodine, rheine, chrysophanol and physcione, in roots of Polygoni multiflori. Phytochem Anal 2009;20: 272-8.

7. Lin SY, Lai WW, Ho CC, Yu FS, Chen GW, Yang JS, et al. Emodin induces apoptosis of human tongue squamous cancer SCC4 cells through reactive oxygen species and mitochondria-dependent pathways. Anticancer Res 2009;29:327-35.

8. Basu S, Ghosh A, Hazra B. Evaluation of the antibacterial activity of Ventilago madraspatana Gaertn., Rubia cordifolia Linn. and Lantana camara Linn.: isolation of emodin and physcion as active antibacterial agents. Phytother Res 2005;19: 888-94.

9. Shrimali D, Shanmugam MK, Kumar AP, Zhang J, Tan BK, Ahn KS, et al. Targeted abrogation of diverse signal transduction cascades by emodin for the treatment of inflammatory disorders and cancer. Cancer Lett 2013:341:139-49.

10. Wang XD, Gu LQ, Wu JY. Apoptosisinducing activity of new pyrazole emodin derivatives in human hepatocellular carcinoma HepG2 cells. Biol Pharm Bull 2007:30:1113-6.

11. Meng G, Liu Y, Lou C, Yang H. Emodin suppresses lipopolysaccharide-induced pro-inflammatory responses and NF$\kappa \mathrm{B}$ activation by disrupting lipid rafts in CD14-negative endothelial cells. Br J Pharmacol 2010;161:1628-44.

12. Wei WT, Lin SZ, Liu DL, Wang ZH. The distinct mechanisms of the antitumor activity of emodin in different types of cancer (Review). Oncol Rep 2013:30:255562.

13. Holliday DL, Speirs V. Choosing the right cell line for breast cancer research. Breast Cancer Res 2011;13:215.

14. Lim YC, Li L, Desta Z, Zhao Q, Rae JM, Flockhart DA, et al. Endoxifen, a secondary metabolite of tamoxifen, and 4-OHtamoxifen induce similar changes in global gene expression patterns in MCF-7 breast cancer cells. J Pharmacol Exp Ther 2006;318:503-12.

15. Chou TC. Theoretical basis, experimental design, and computerized simulation of synergism and antagonism in drug combination studies. Pharmacol Rev 2006;58: 621-81.

16. Chung YS, Cho S, Ryou HJ, Jee HG, Choi JY, Yoon $\mathrm{K}$, et al. Is there a treatment advantage when paclitaxel and lovastatin are combined to dose anaplastic thyroid carcinoma cell lines? Thyroid 2011;21:73544.

17. Levenson AS, Jordan VC. MCF-7: the first hormone-responsive breast cancer cell line. Cancer Res 1997;57:3071-8.

18. Burdall SE, Hanby AM, Lansdown MR, Speirs V. Breast cancer cell lines: friend or foe? Breast Cancer Res 2003;5:89-95.

19. Sartorius CA, Groshong SD, Miller LA,
Powell RL, Tung L, Takimoto GS, et al. New T47D breast cancer cell lines for the independent study of progesterone B- and A-receptors: only antiprogestin-occupied B-receptors are switched to transcriptional agonists by cAMP. Cancer Res 1994:54:3868-77.

20. Neve RM, Chin K, Fridlyand J, Yeh J, Baehner FL, Fevr T, et al. A collection of breast cancer cell lines for the study of functionally distinct cancer subtypes. Cancer Cell 2006;10:515-27.

21. Pontano LL, Diehl JA. Speeding through cell cycle roadblocks: nuclear cyclin D1dependent kinase and neoplastic transformation. Cell Div 2008;3:12.

22. Zhang X, Gureasko J, Shen K, Cole PA, Kuriyan J. An allosteric mechanism for activation of the kinase domain of epidermal growth factor receptor. Cell 2006; 125:1137-49.

23. Lahusen T, Fereshteh M, Oh A, Wellstein A, Riegel AT. Epidermal growth factor receptor tyrosine phosphorylation and signaling controlled by a nuclear receptor coactivator, amplified in breast cancer 1 . Cancer Res 2007;67:7256-65.

24. Saini KS, Loi S, de Azambuja E, MetzgerFilho O, Saini ML, Ignatiadis M, et al. Targeting the PI3K/AKT/mTOR and Raf/MEK/ ERK pathways in the treatment of breast cancer. Cancer Treat Rev 2013;39:935-46.

25. Mohammend MM. Structure antimutagenicity relationship of anthraquinones. Nat Prod Chem Res 2016;4:1000228.

26. Jones JL, Daley BJ, Enderson BL, Zhou JR, Karlstad MD. Genistein inhibits tamoxifen effects on cell proliferation and cell cycle arrest in T47D breast cancer cells. Am Surg 2002;68:575-7.

27. Ju YH, Doerge DR, Allred KF, Allred CD, Helferich WG. Dietary genistein negates the inhibitory effect of tamoxifen on growth of estrogen-dependent human breast cancer (MCF-7) cells implanted in athymic mice. Cancer Res 2002;62:2474-7. 